\title{
Modelling of ambient air quality, Coimbatore, India
}

\author{
Sarojini. Eswaran ${ }^{I^{*}}$, Bharathiraj. L.T ${ }^{2}$ and Jayanthi. $\mathrm{S}^{3}$ \\ ${ }^{1}$ Professor and Head, Civil Engineering, Sri Ramakrishna Engineering College, Coimbatore \\ ${ }^{2}$ Student of Civil Engineering, Sri Ramakrishna Engineering College, Coimbatore \\ ${ }^{3}$ Principal, Government College of Engineering, Bodinayakanur, Theni
}

\begin{abstract}
Air pollution is dispersion of the particulates, biological molecules, or other harmful materials into the Earth's atmosphere, possibly causing diseases. Air pollutants can be either particles, liquids or gaseous. In the recent era, air pollution has become a major environmental issue because of the enhanced anthropogenic activities such as burning fossil fuels, natural gases, coal and oil, industrial process, advanced technologies and motor vehicles. The proposed project focused on air pollution study of North Coimbatore region $\left(11^{\circ} 0^{\prime} 16.4016^{\prime \prime} \mathrm{N}\right.$ and $\left.76^{\circ} 57^{\prime} 41.8752^{\prime \prime} \mathrm{E}\right)$, Tamilnadu, India. The area comprises of industries, residential and commercial areas, where plenty of pollution occurs due to emissions from automobiles also. The main aim of the project is to develop models using GIS for the air pollutant concentration of Coimbatore region. In order to run the model, the concentration details of $\mathrm{PM}_{2.5}$ (Particulate mass) were collected. Prediction models have been evolved for the monitoring station to predict the concentration of pollutants (PM2.5) based on the different meteorological parameters and also vice versa. The project concludes that highly polluted places are Koundampalayam and Thudiyalur compared to all other monitoring stations.
\end{abstract}

\section{Introduction}

Air pollutants are substances that emits from the natural as well as industrial activity and it consists of gaseous pollutants, odours, Total Suspended particulate matter (TSPM) and Respiratory suspended particulate matter (RSPM) such as dust, fumes and smoke. The concentration of PM near the urban areas causes severe pollution to the surroundings and increase Urban Heat Islands (UHI).

The air pollutants are classified as two major groups, [10]

- Primary pollutants

- Secondary pollutants

Primary pollutants are emitted directly into the air such as Carbon monoxide, Sulphur dioxide, Nitrogen oxides, Hydrocarbon and particulates. The main primary pollutants known to cause harm in high enough concentrations are the following:

Carbon compounds, such as $\mathrm{CO}, \mathrm{CO}_{2}, \mathrm{CH}_{4}$, and VOCs

Nitrogen compounds, such as $\mathrm{NO}, \mathrm{N}_{2} \mathrm{O}$, and $\mathrm{NH}_{3}$

Sulphur compounds, such as $\mathrm{H}_{2} \mathrm{~S}$ and $\mathrm{SO}_{2}$

Halogen compounds, such as chlorides, fluorides, and bromides

Particulate Matter (PM or aerosols), either in solid or liquid form, which is usually categorized into these groups based on the aerodynamic diameter of the particles.

1. Secondary pollutants are formed by Primary pollutants interact with one another, sunlight, or natural gases to produce new harmful compounds. Some of the secondary pollutants are listed below:

Ozone $\left(\mathrm{O}_{3}\right)$ formed from photochemical reactions of nitrogen oxides and VOCs

Peroxy - Acyl Nitrate (PAN)

Photo - chemical smog, etc.

\subsection{Significance of Suspended Particulate Matter}

Suspended Particles may be of any shape or size, and can be solid particles or liquid droplets. One of the differences is size, named the macro particles as $\mathrm{PM}_{10}$ and the micro particles as $\mathrm{PM}_{2.5}$.

$\mathrm{PM}_{10}$ particles cause less severe health effects and they can be characterized by their physical attributes, which influence their transport and deposition, and the chemical composition influences on health. The physical attributes of airborne particulates include mass concentration and size distribution. The main sources are crushing and grinding rocks, soil and then blown by wind.

The small particles are smaller than 2.5 micrometers (100 times thinner than a human hair) are called $\mathbf{P M}_{2.5}$.

\footnotetext{
*Sarojini Eswaran: hod-civil@ srec.ac.in
} 
Particles emitted directly include soil- related and organic carbon particles from the combustion of fossil fuels and biomass burning. The main sources are combustion related particles i.e driving automobiles, burning plants (brush fires and forest fires or yard waste), smelting (purifying) and processing metals.

Sulphate, Acid (e.g. hydrogen ion, H+), nitrate, organic and elemental carbon, trace elements, ammonium and water are often the major constituents of $\mathrm{PM}_{2.5}$. The major sources of these substances are fossil fuels combustion by electric utilities, industry and motor vehicles, vegetative burning and smelting or other processing of metals.

\subsection{Health effects}

The particles most likely to cause health effects are the fine particulates, in particular particles smaller than 10 micron and 2.5 micron in aerodynamic diameter, respectively. Coarse particle around 5 to 40 microns diameter are partially retained in nose and partially in the trachea and the bronxchi. Very fine particles 0.5 to 5 micron diameter contain microscopic solids or liquid droplets that are so small that they can get deep into the lungs and cause serious health problems. Numerous scientific studies have linked particle pollution exposure to a variety of problems, including:

- premature death in people with heart or lung disease,

- nonfatal heart attacks,

- irregular heartbeat,

- aggravated asthma,

- decreased lung function

- Increased respiratory symptoms, such as irritation of the airways, coughing or difficulty breathing.

- People with heart or lung diseases, children and older adults are the most likely to be affected by particle pollution exposure.

\subsection{Environmental Effects}

Particles can be carried over long distances by wind and then settle on ground or water. The effects of the settling includes: making lakes and streams acidic; changing the nutrient balance in coastal waters and large river basins; depleting the nutrients in soil; damaging sensitive forests and farm crops; and affecting the diversity of ecosystems. Particle pollution can stain and damage stone and other materials, including culturally important objects such as statues and monuments.

\subsection{Objectives of the study}

The project study involves the following objectives.

- To monitoring the concentration of Particulate matter $\mathrm{PM}_{2.5}$ present in air

- To evaluate the levels of exposure to pollutants at different locations within North Coimbatore cluster.

- To compare the measured values with the recommended threshold limit values as notified in the National Ambient Air Quality Standards (NAAQS) by the Central Pollution Control Board (CPCB).

- To generate the ambient air quality modeling using GIS

\section{Study area}

\section{Coimbatore District}

Coimbatore District is located in the western part of Tamil Nadu. The District is spread out in an area of 7469 sq.km. The average annual rainfall in the plan is around $700 \mathrm{~mm}$. Coimbatore city is located at $11^{\circ} 1^{\prime} 6^{\prime \prime} \mathrm{N}$ and $76^{\circ} 58^{\prime} 21^{\prime \prime} \mathrm{E}$, at about $411.2 \mathrm{~m}$ above mean sea level. The city is also known as Manchester of South India. The city is famous for textile spinning mills, wet grinders, pumps and motors industry sector. To cater the needs of above and to fabricate machineries for the factories, foundry and electroplating sector establishments are emerging.

\subsection{Sampling Location}

The samples are collected in 5 places in North Coimbatore respectively,Thudiyalur(11.0805,76.9416),Saravanampatty (11.0783,77.0036), Koundampalayam (11.0450,76.947), Pannemadai (11.0852,76.9229), Periyanayakanpalayam $(11.1457,76.9437)$. The major industries in the areas are Texmo industries, CRI pumps, Ammarun foundries, LMW, L.G.B limited, Pricol, and small and medium foundries; the pollution is also caused by movement of automobiles.

\subsection{Monitoring of air quality}

For the collection of $\mathrm{PM}_{2.5}$ fine particulate sampler instrument as shown in Fig 1 is used. This sampler used to collect the $\mathrm{PM}_{2.5}$ mass in the surrounding air. The instrument consists of following parts,

1.Omni directional inlet tube.

2.Wins impactor.

3. Vaccum pump.

4. Volume indicator and timer.

Constant sampling rate of $1 \mathrm{~m} 3 / \mathrm{hr}$ will be unaffected by voltage fluctuation and filter choking maintained by critical orifice system. Oil Free, non-pulsating pump driven by induction motor for stable flow rate is used. Dry Gas meter records the total air volume sampled. Omni-directional air inlet with $\mathrm{PM}_{10}$ separation through an impactor followed by through a WINS Impactor.

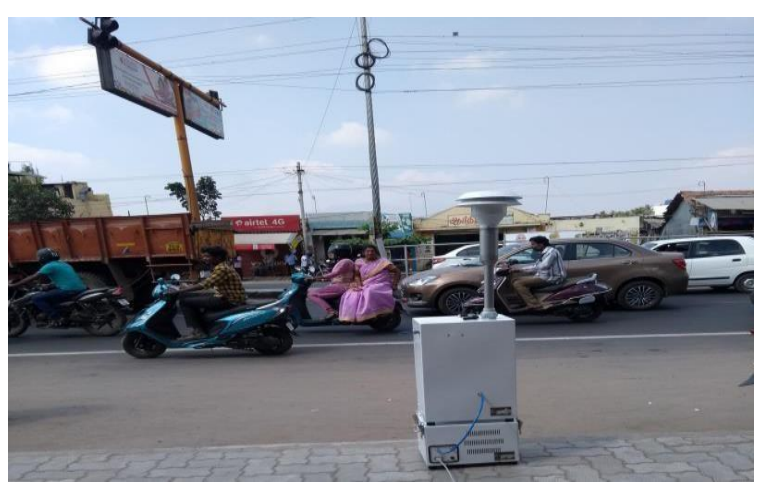

Fig 1.Fine Particulate sampler

- $\quad$ Filter handling is critical for $\mathrm{PM}_{2.5}$ analysis. After the run time, Filters should be removed as soon as possible from the sampler and covered immediately. 
Filter need to be equilibrated in a controlled environment for $24 \mathrm{~h}$ before final weighing.

- The controlled environment requirements for $\mathrm{PM}_{2.5}$ are more conservative than for $\mathrm{PM}_{10}$. Temperature must be controlled at 20 to $23^{\circ} \mathrm{C}\left( \pm 2^{\circ} \mathrm{C}\right)$ and humidity must be controlled at 30 to $40 \%( \pm 5 \%)$. From the calculation the $\mathrm{PM}_{2.5}$ values are obtained

The equation is used to determine $\mathrm{PM}_{2.5}$ mass concentration:

$\mathrm{PM}_{2.5}=\mathrm{M}_{2.5} / \mathrm{V}$

Where, $\mathrm{PM}_{2.5}=$ mass concentration of $\mathrm{PM}_{2.5}$ particulates $\left(\mu \mathrm{g} / \mathrm{m}^{3}\right)$.

$\mathbf{M}_{2.5}=$ total mass of fine particulate collected during sampling period $(\mu \mathrm{g})$.

$\mathrm{V}=$ total volume of air sampled $\left(\mathrm{m}^{3}\right)$.

\subsection{Sampling}

The samples are collected in the Thudiyalur, Saravanampatty, Koundampalayam, Pannemadai, Periyanayakanpalayam location with respective time, peak hours (7am-11am) and non-peak hours(11am-3pm). Sample of particulate collection in filter paper is shown in Fig 2. Air quality monitoring at above mentioned stations were collected for the month of February and March 2019 at sampling locations.
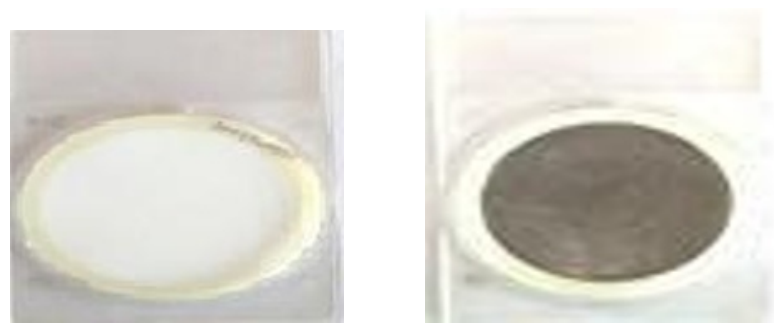

Fig 2. Sample of Pollutant concentration

\subsection{Data used for Modelling}

Ambient air quality data like concentrations of pollutants such as particulate matter PM 2.5 , were obtained from experimental studies. The meteorological data such wind direction, wind speed, temperature and relative humidity values are obtained for study period of 2019. Based on the meteorological parameters and months, the pollutant concentration is predicted for all monitoring stations. Sample of Air pollutant concentration and Meteorological data used in GIS Modelling are shown in Table 2.1 and Table 2.2.
Table 2.1 Sample of Air pollutant

\begin{tabular}{|c|c|c|c|}
\hline \multirow[b]{2}{*}{ Date } & \multicolumn{3}{|c|}{ Particulate Matter } \\
\hline & Location & $\begin{array}{c}\text { PM}_{2.5} \\
\mu^{3} / \mathbf{m}^{3} \\
\text { (Peak } \\
\text { HOUR) }\end{array}$ & $\begin{array}{c}\mathrm{PM}_{2.5} \mu \mathrm{g} / \mathrm{m}^{3} \\
\text { (Nonpeak } \\
\text { HOUR) }\end{array}$ \\
\hline $11 / 02 / 19$ & \multirow{5}{*}{$\begin{array}{c}\text { Thudiyalur } \\
(11.0805, \\
76.9416)\end{array}$} & 68 & 53 \\
\hline $12 / 02 / 19$ & & 55 & 42 \\
\hline $13 / 02 / 19$ & & 58 & 37 \\
\hline $14 / 02 / 19$ & & 50 & 35 \\
\hline $15 / 02 / 19$ & & 65 & 49 \\
\hline $18 / 02 / 19$ & \multirow{5}{*}{$\begin{array}{c}\text { Saravanampatty } \\
(11.0783, \\
77.0036)\end{array}$} & 59 & 41 \\
\hline $19 / 02 / 19$ & & 48 & 25 \\
\hline $20 / 02 / 19$ & & 47 & 40 \\
\hline $21 / 02 / 19$ & & 40 & 28 \\
\hline $22 / 02 / 19$ & & 63 & 37 \\
\hline
\end{tabular}

Table 2.2 Sample of Meteorological data used for GIS Modelling

\begin{tabular}{|c|c|c|l|c|}
\hline \multirow{2}{*}{ Date } & \multicolumn{4}{|c|}{ Meteorological parameters } \\
\cline { 2 - 5 } & $\begin{array}{c}\text { W Dirn } \\
\text { (Deg) }\end{array}$ & $\begin{array}{c}\text { Temp } \\
\text { (Deg C) }\end{array}$ & $\begin{array}{c}\text { Relative } \\
\text { Humidity } \\
(\%)\end{array}$ & $\begin{array}{c}\text { Speed } \\
(\mathbf{K m} / \mathbf{h r})\end{array}$ \\
\hline $11 / 02 / 19$ & 89.59 & 25.84 & 56.24 & 3.73 \\
\hline $12 / 02 / 19$ & 85.75 & 25.23 & 51.28 & 4.32 \\
\hline $13 / 02 / 19$ & 83.06 & 25.15 & 46.07 & 3.53 \\
\hline $14 / 02 / 19$ & 99.05 & 25.83 & 51.33 & 2.9 \\
\hline $15 / 02 / 19$ & 111.81 & 27.23 & 52.51 & 1.58 \\
\hline $18 / 02 / 19$ & 146.64 & 29.85 & 38.93 & 1.29 \\
\hline $19 / 02 / 19$ & 112.47 & 29.35 & 48.54 & 2.99 \\
\hline $20 / 02 / 19$ & 97.69 & 28.26 & 48.3 & 3.99 \\
\hline $21 / 02 / 19$ & 84.78 & 27.18 & 44.12 & 3.43 \\
\hline $22 / 02 / 19$ & 85.06 & 26.2 & 35.8 & 3.57 \\
\hline
\end{tabular}

\subsection{Software used in Study ArcGIS}

ArcGIS Software is used to carry out the spatial analysis. Inverse distance weighing interpolation technique is used in the software to run the analysis. Ambient air quality data like concentration of pollutants such as $\mathrm{PM}_{2.5}$ particulate matter) and meteorological parameters with month are used to run the GIS. Two models are developed using concentration of pollutants of $\mathrm{PM}_{2.5}$ measured in peak and nonpeak hours and with meteorological parameters as inputs and gives output as analysis for North Coimbatore. 


\section{Results and Discussions}

From the standard limits proposed by CPCB, the concentration above $60 \mu \mathrm{g} / \mathrm{m}^{3}$ stations denotes as polluted areas. From the project, pollutants are high around the Koundampalayam and Thudiyalur, compared to Pannemadai. Area around the Saravanampatty and Periyanayakanpalayam are moderately polluted are shown in Fig 3 and Fig 4 for Peak and Nonpeak hours.

Koundampalayam - $79 \mu \mathrm{g} / \mathrm{m}^{3}$.

Thudiyalur - $68 \mu \mathrm{g} / \mathrm{m}^{3}$.

Periyanayakanpalayam - $63 \mu \mathrm{g} / \mathrm{m}^{3}$.

Saravanampatty - $63 \mu \mathrm{g} / \mathrm{m}^{3}$.

Pannemadai - $59 \mu \mathrm{g} / \mathrm{m}^{3}$.

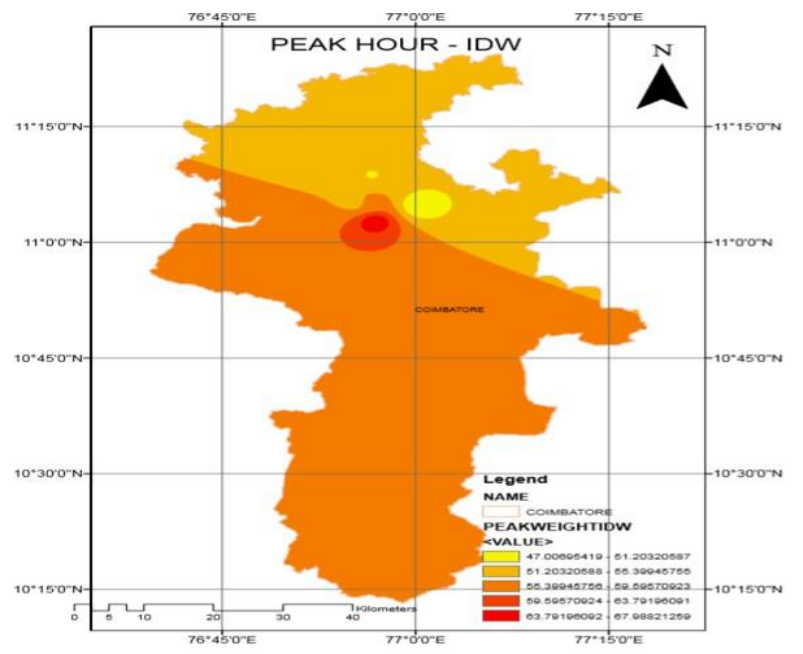

Fig 3: Modelling of peak hour air pollution

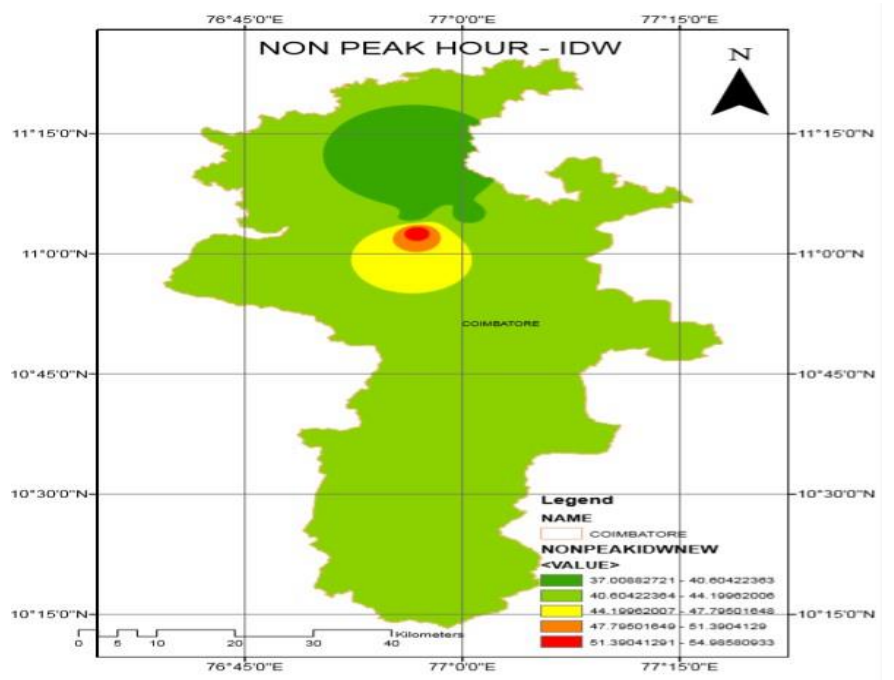

Fig 4: Modelling of Non peak hour air pollution

\section{Conclusions}

Air pollution models can be a very effective tool in planning strategies for management of local air quality and can provide a rational basis for the control of air pollution. If properly designed and evaluated, air pollution models play a considerable role in any air quality management system. From the project, GIS model predicts highly polluted sampling stations are Koundampalayam and Thudiyalur compared to all other stations.

For the prevention of pollutants in environment, the following care should be taken,

- At the community level, air pollutants can be reduced by choosing to walk, cycle or take public transport rather than drive a car.

- Maintain automobiles in good condition and drive to reduce fuel consumption, minimize emissions and impacts are likely to be minimal.

- Industries can use pollution control devices to remove pollutants by installing air pollution control equipments, and by absorbing, filtering, diluting or dispersing them.

- Increasing plants and trees in industries and trees along roads will reduce UHI.

\section{References}

1. Alan J. Cimorelli, Steven G. Perry, Akula Venkatram, Jeffrey C. Weil, Robert J. Paine, Robert B. Wilson, Russell F. Lee, Warren D. Peters, AND Roger W. Brode, "AERMOD: A Dispersion Model for Industrial Source Applications. Part I: General Model Formulation and Boundary Layer Characterization" 682 Journal of Applied Meteorology, Volume 44, October (2004).

2. Balaceanu C., Stefan S. The assessment of the TSP particulate matter in the urban ambient air, Romanian Reports in Physics, Vol 56 , No 4, 757768. (2004)

3. Daewon Byun and Kenneth L. Schere, "Review of the Governing Equations, Computational Algorithms, and Other Components of the Models3 Community Multiscale Air Quality (CMAQ) Modeling System" Accepted by Applied Mechanics Reviews, September (2004)

4. Holly Janes, Lianne Shepherd and Kristen Shepherd, "Statistical Analysis of Air Pollution Panel Studies: An Illustration" Ann Epidemiol 18:792-802, (2008)

5. Kalabokas, P.D, "Atmospheric PM10 particle concentration measurements at Central and peripheral urban sites in athens and Thessaloniki, Greece, Global NEST Journal, Vol 12, No 1, pp 7183 (2010).

6. Liang Jing, April, "Linear Regression for Air Pollution Data" University of Texas at San Antonio, (2008).

7. Maraziotis. E et al. "Statistical analysis of inhalable $\left(\mathrm{PM}_{10}\right)$ and fine particles ( $\left.\mathrm{PM} 2.5\right)$ concentrations in urban region of Patras, Greece", Global NEST Journal, Vol 10, No 2, pp 123-131(2008)

8. Meenakshi P., M. K. Saseetharan, "Analysis of Seasonal Variation of Suspended Particulate Matter and Oxides of Nitrogen with Reference to Wind Direction in Coimbatore City" IE (I) Journal. EN Vol. 84, September (2003)

9. Powe Neil A., Willisc Kenneth G. Mortality and morbidity benefits of air pollution absorption by 
Woodland, Social \& Environmental Benefits of Forestry Phase 2 , (2002).

10. Rao M. N and Rao H.V.N., "Air Pollution Control", 1st Edition, Tata-McGraw Hill, (2005).

11. Sotiris Vardoulakisa,, Bernard E.A. Fisherb, Koulis Pericleousa, Norbert Gonzalez-Flescac, September 2002, "Modelling air quality in street canyons: a review" Atmospheric Environment, 37 155-182 (2003).

12. Tirthankar Banerjeeet al.,"Assessment of the ambient air quality at the Integrated Industrial Estate-Pantnagar through the air quality index (AQI) and exceedence factor (EF)", Asia-Pac. J. Chem. Eng. 6: 64-70 (2011). 